\title{
8 Transit safety among college students in Tokyo-Kanagawa, Japan
}

\author{
Victimization, safety perceptions \\ and preventive measures
}

\section{Seiji Shibata}

\subsection{Introduction}

Japan has a highly developed and extensive railway system. The railways are an essential daily means of transportation within the country. However, the increase in the number of criminal offences on railways during the early 2000s resulted in heightened public concern over passenger safety and the security of the railway system. The number of violent offences and nuisance crimes remains high even though the total instances of criminal offences have decreased rapidly in the country since the turn of the century (Nomura, 2017).

This study investigates the nature of women's transit safety in TokyoKanagawa by examining women's safety perceptions and victimization while in transit and exploring the relationship between women's experiences of victimization and their perceptions of crime preventive measures available in transit environments; in particular, surveillance cameras and women-only carriages.

College students were selected for the investigation as the Tokyo Metropolitan Police Department (2018) reported evidence that young women (in their teens and 20s) are most vulnerable to groping, a form of sexual harassment. This age group also relies heavily on railway services as a daily mode of commuting.

This chapter's study is novel as it is based on a recently available dataset collected in Tokyo as a study case, and which forms part of a global investigation conducted in conjunction with other cities by researchers from six continents: Africa, Asia, Australia/Oceania, Europe, North America and South America (Ceccato and Loukaitou-Sideris 2019). Although the results of the surveys in other countries are not reported in this chapter, our results contribute to understanding the current overall situation of transport safety for women by highlighting some of the trends in victimization and safety perceptions in Tokyo that are also found elsewhere.

\subsection{Background of Tokyo's transportation}

In large metropolitan areas such as Tokyo and Kanagawa, railway and subway lines serve as essential means for commuting in Japan. According to a report by East Japan Marketing and Communications, Inc. (2016), the cumulative number 
of weekly passengers in the Greater Tokyo Area, which includes Tokyo, Kanagawa, and other prefectures surrounding Tokyo, totals over 93 million, such that the daily number of 13 million passengers amounts to approximately one-third of the residential population in this area $(38$ million). A road traffic census conducted in 2010 demonstrated that railways, including subways, comprised 44.5 percent of Tokyo's commuting modes, compared with 2.5 percent by buses, and 9.4 percent by personal car (Statistics Bureau, Ministry of Internal Affairs and Communications, 2010).

In Tokyo Metropolis (population 13.7 million) alone, more than ten railway companies operate trains and subways. The number of lines operating in Tokyo exceeds 50, and along with the additional lines in the surrounding densely populated prefectures such as Kanagawa (population nine million), a total of nearly 100 lines are currently operating in Tokyo and Kanagawa. Unlike other countries, many of the railway and subway lines in Tokyo-Kanagawa are interconnected and share the same tracks. In addition, railway companies operate through a wide network of operatives, railways and subways, thus forming a sizeable and complex railway network. For this reason, hereafter in this chapter, we refer to both the railway and the subway as "the railway".

Although Tokyo's railway services are highly efficient and famed for their punctuality, they are also notorious for extreme rush-hour traffic. During morning rush hours, the congestion rate exceeds 180 percent, which is set as the upper limit for peak travel hours, and the rate approaches 200 percent on some commuter lines. According to the guidelines of the Japan Ministry of Land, Infrastructure and Transport, a congestion rate of 100 percent is one in which all passengers can have a seat, or hold on the straps or handrails, and passengers come into direct physical contact at a congestion rate of 180 percent, and such contact becomes oppressive at a congestion rate of 200 percent.

\section{The problem of groping on public transport}

In this context, a significant problem associated with railway travel in Japan, especially in Tokyo, is chikan, that is, groping or molestation. According to a survey by Japan's Gender Equality Bureau Cabinet Office (2000), 48.7 percent of women aged over 20 years reported at least one experience of being groped. The Tokyo Metropolitan Police reported that 51.3 percent of indecent acts, including groping, occurred on trains and an additional 20 percent took place in station buildings, such that over 70 percent of such incidents occurred in the context of railway use (cf. 0.8 percent in buses, Tokyo Metropolitan Police Department, 2018).

Most of the victims of groping are women, particularly younger women. According to the Tokyo Metropolitan Police, 42.6 percent of the victims of groping were in their 20 s, whereas 28.3 percent were between the ages of 10 and 20 and 11.3 percent were in their 30s (Tokyo Metropolitan Police Department, 2018). A survey of college students revealed that 37 percent of female students (and 6 percent of male students) reported they had experienced 


\section{Seiji Shibata}

groping while riding on a train (Otaka, 2017). An earlier survey that targeted women aged 18 to 29 showed that 33.7 percent of them had experienced groping in the last three years (Suzuki, 2000).

In Japan, groping is primarily categorized as a type of "public nuisance crime" and is controlled by the anti-nuisance ordinance, with some severe cases prosecuted as indecent assault. According to a white paper on crime published in 2015, the number of reported groping incidents (including in places other than trains) in 2006 was 4,601 throughout the country (National Police Agency, 2015).

The fact that groping is primarily controlled by the anti-nuisance ordinance rather than criminal law suggests that groping is legally considered a "minor" offence compared with other forms of sexual assault, such as rape. However, as Omata $(2002,2012)$ indicated, groping is the most common indignity endured by young women in Japan during their everyday lives, and experiences of being victimized by sexual groping have been found to be the most influential factors on their criminal risk perception and fear of crime. Research suggests women in other countries also suffer from forms of sexual harassment during transit (Ceccato, 2017; Dunckel-Graglia, 2013; Gekoski, Gray, Adler, \& Horvath, 2017; Madan \& Nalla, 2016; Neupane \& Chesney-Lind, 2014). However, as Loukaitou-Sideris and Fink (2009) indicated, the issue of women's safety on transit has received considerably less attention compared with the problem of women's fear of crime in other public spaces.

\section{Women-only cars as a countermeasure against groping}

In 2000, Keio Electric Railway, one of the railway companies operating in Tokyo, introduced women-only cars on a trial basis on late-night services, in response to complaints of groping on trains, before introducing them as a regular service the following year. In 2001, East Japan Railway (JR East), the largest railway company in Tokyo and adjacent areas, also began operating women-only cars on the Saikyo line, which was known for having the highest reported number of groping-related incidents. Other railway companies followed the lead and, in 2005, many of the railway companies in the Greater Tokyo Area began offering women-only car services on the commuter lines (Doi, 2005). Currently, most commuter lines in Tokyo have women-only car services, which typically operate during morning rush hours.

According to Whitzman (2013) and Lee (2017), several other countries have women-only train cars. The countries noted in their articles were Brazil, Mexico, Egypt, Iran, India, Pakistan, Indonesia, Malaysia, and South Korea. According to Whitzman (2013), 50 percent of the women in Bangladesh desired this type of service while only 2 percent of women in India deemed it to be a viable option. Dunckel-Graglia (2013) showed that over 50 percent of female respondents in Mexico City reported they always use women-only cars. Thus, the endorsement of women-only train cars differs from country to country. The results of a survey by Statistics Bureau, Ministry of Internal Affairs 
and Communications (2002) revealed the women-only car service is welcomed on the whole in Japan: 77 percent women and 66 percent men were in favor of the concept.

However, the effectiveness of the introduction of women-only cars on commuter lines as a countermeasure against groping has not been well-studied in Japan. According to the National Police Agency's (2015) white paper on crime, the total number of reported groping incidents decreased from 4,601 in 2006 to 3,722 in 2014; however, the number of such incidents occurring before 2006 was not included in their report; therefore, it remains unclear whether there was any significant change after the full-scale introduction of women-only cars. Additionally, our ability to identify the actual change in groping prevalence is limited because no railway operators currently disclose groping report rates to the public.

Several incidents have occurred in recent years in which groping suspects have fled on the tracks, causing immense delays or cancellations. Such delays or cancellations result in serious problems during rush hours because there are no alternative modes of transportation that can carry as many passengers as the railways. Groping is thus becoming a big problem for railway operations.

\section{CCTV cameras as a security measures on trains and platforms}

Railway companies in Tokyo installed surveillance cameras on station platforms and station buildings after the sarin gas attack on a Tokyo subway in 1995. However, surveillance cameras were not introduced on train cars until recently because of privacy concerns. As the number of criminal offences committed in trains increased in the early 2000s (Nomura, 2017), several railway companies began introducing surveillance cameras in train cars as a security measure over the last few years with the hope of deterring violence and groping.

Additionally, the 2020 Tokyo Olympic Games have driven the movement to place surveillance cameras on train cars, as world events such as the Olympic Games can become targets for terrorist attacks. JR East announced its plan to install surveillance cameras on all passenger cars on the Yamanote Line by the proposed start of the 2020 Olympic Games (Kyodo News, 2018). This central Tokyo loop route carries the largest number of passengers.

The Ministry of Internal Affairs and Communications Statistics Bureau survey of 2002 reported that 52.4 percent of men and 57.1 percent of women favored the installation of survey cameras on train cars as a measure for the prevention of groping and violence. However, a number of the respondents (26.9 percent of men and 22.0 percent of women) expressed dissatisfaction, asserting that it was unpleasant to be monitored by cameras and that such surveillance was ineffective because acts of groping could not be captured by the cameras because of the over-crowdedness of the trains.

Research on the railways in Japan is centered primarily on engineering aspects, such as the safety of facilities and systems. Although several surveys have 


\section{Seiji Shibata}

been conducted on such matters, limited scientific research has examined citizen's attitudes toward women-only cars or surveillance cameras on trains. The Statistics Bureau of the Ministry of Internal Affairs and Communications (2002) conducted a survey in March 2002 on women-only cars and surveillance cameras in the Tokyo area as part of a larger study of women's perspectives on transport services. However, this study is not only dated but was done before women-only cars had been fully operational on Tokyo area commuter lines. Over 15 years have passed since women-only cars were introduced full-scale into the commuter lines and surveillance cameras were rapidly installed in and around Tokyo, necessitating the current investigation.

\subsection{Data and methods}

Participants were recruited for the survey from panel members of a web survey company and comprised 400 college students (196 men, 196 women, and eight other) living in Tokyo/Kanagawa (age range 18 to 29). The web company collected an extensive database of panel members through various online services, such as e-commerce sites by offering respondents loyalty program points for survey participation. Potential respondents for the survey were randomly extracted from the targeted student pool and the people identified were subsequently asked to participate in the survey. The questionnaire was administered by the survey company via a web system until the quota (total 400 , and maleto-female ratio $1: 1$ ) was met.

The data collected from those who identified their gender as other than male or female were excluded from the analysis because their numbers were too small. Data from two other participants (one male and one female) were also excluded from the dataset because they answered that they never use the railway for commuting. The total sample size of our dataset was 390 (male=195, female $=195)$ with most $(N=381,97.69$ percent $)$ being Japanese and nine representing other nationalities (four East Asian, two Asian, and three mixed). Over three-quarters of the participants reported using the railway almost daily, and their commuting times ranged from 30 to 120 minutes. No gender differences were observed in the frequency of railway use and the commuting time (Table 8.1).

The questionnaire used in the survey was based on the aforementioned international research project on women's transit safety and administered in Japanese. The questionnaire included the following main topics: (1) the frequency of railway use and the length of commuting time; (2) safety and security perceptions of the railway; (3) experiences of harassment using railways and reporting of those experiences; and (4) effectiveness of security and safety measures.

To measure the frequency of railway use, participants were asked how often they used the railway in a typical week, with potential answers ranging from "never" to "every day". As mentioned above, data from those who answered "never" to this question were excluded from the dataset. Additionally, participants provided their typical door-to-door travel times on an average weekday. 
Table 8.1 Summary of the participants' frequency of railway use and commuting time

\begin{tabular}{llllll}
\hline \multicolumn{5}{l}{ Frequency of railway use } \\
\cline { 2 - 6 } & Everyday & $5-6$ days & $3-4$ days & 1-2 days & Less than once \\
\hline Women & 70 & 75 & 26 & 20 & 4 \\
Men & 62 & 81 & 29 & 19 & 4 \\
\hline \multirow{5}{*}{ Commuting time } & & & & \\
\cline { 2 - 6 } & More than 2 hrs. & $1-2$ hrs. & 30 min. -1 hr. & $15-30$ min. & Less than 15 min. \\
Women & 11 & 84 & 78 & 12 & 10 \\
Men & 11 & 91 & 61 & 16 & 16 \\
\hline
\end{tabular}

Note

$N=195$ for both men and women.

The questions on safety and security perceptions comprised four items on how often participants felt safe when they rode the train and were waiting on the station platform during the daytime and night-time, respectively. Responses were coded on a scale ranging from 1 (Always) to 5 (Never) and 6 for those who did not use it. The participants were also asked several multiple choice questions for which they could select all applicable answers. These included what the respondents considered to be significant problems on trains and platforms (e.g., darkness/poor lighting, litter or drunk people), and what prevented them from using the railway more frequently (e.g., cost, fear of a crash).

To measure their experiences with harassment, participants were queried on whether they had experienced harassment or criminal acts on the trains, platforms, and/or on their way to/from the station in the past three years. Also, participants were asked whether they had reported that experience to someone, and if they answered "yes", they were asked to whom they reported it (e.g., police, railway companies, their parents). For those who answered "no", they were asked to provide the reason for not reporting.

To determine their perceptions of the effectiveness of security and safety measures, participants were asked to choose the three most effective methods they believed would make railway travel safer from among a list of choices (Table 8.2).

The survey was conducted online in Japan from 6-13 June 2018, and was hosted by a commercial survey company (http://cross-m.co.jp). All the participants answered the questionnaire via a web system and received loyalty program points from the survey company as an incentive for completing the questionnaire. The entire survey, including questionnaires on other modes of transport, took approximately 25 minutes to complete.

In the analysis, effect sizes for proportion (Cohen's $h$ ) and association coefficients $(\varphi)$ were calculated to evaluate the size of the differences. Cohen's $b$ is a measure of the difference between two probabilities or proportions. It helps to 
determine whether the difference is not too small to be meaningful. The rule of thumb criteria set out by Cohen (1988) says the effect size is small when $b$ equals 0.2 , medium when it is equivalent to 0.5 , and large when it amounts to 0.8 .

\subsection{Results}

\section{Victimization of sexual harassment and transit crime}

Most of the participants indicated they had never experienced any type of harassment or crime listed in the questionnaire (for women, it varied from 65 percent to 84 percent depending on the settings and, for men, approximately 90 percent in all three settings, namely on trains, on platforms, and to/from the station). However, gender differences in harassment experience were evident. The total number of people who reported having experienced any of these forms of harassment included 28 men and 125 women; therefore, more than four times as many women as men experienced harassment. The most significant difference between men and women was observed in the rates of groping on the train (2.6 percent of men vs. 24.1 percent of women), such that the effect size of the gender difference was $h=0.70$. Additionally, there were medium-size gender differences in the rates of stalking on the way to/from the station ( 1.0 percent of men vs. 10.8 percent of women, $h=0.47$ ).

The number women who reported they had experienced at least one form of harassment was 68 (34.9 percent), and the number of women who reported they had been exposed to groping was 47 , which comprised nearly 70 percent of the women who had experienced harassment on a train. This number is also more than twice that of women who reported being stalked on the way to/ from the station, which was the second most experienced harassment among the female participants $(b=0.36)$. These results indicate that groping on the train car is by far the most common problem for women using railway transport.

Among the women who had reported they had been groped, 26 (55.3 percent) answered that they had not reported the incident to anyone. The most frequent reason for not reporting was "to avoid more trouble" $(15 / 26=57.7$ percent $)$ followed by "I was embarrassed" $(12 / 26=46.2$ percent). Additionally, women who answered they had reported their experience to someone reported mostly to a friend of theirs $(15 / 19=79.0$ percent $)$, and only four women answered they had reported it to the police or the train conductor/operator (two to the police and another two to the train conductor/ operator). Thus, the number of women who had reported it to officials was four out of a total of 47 persons ( 8.5 percent) who had been exposed to groping on trains.

Table 8.2 shows the actual experiences and perceptions of groping on trains among female participants. Pearson's chi-squared test with Yates' correction showed there were significant differences in the perception of sexual harassment on trains between those who had experienced groping on the train and those 
Table 8.2 Cross-tables between the experiences and perceptions of groping on trains among female participants

\begin{tabular}{|c|c|c|c|c|c|c|}
\hline \multirow{2}{*}{$\begin{array}{l}\text { Experience of } \\
\text { groping }\end{array}$} & \multicolumn{3}{|c|}{ Significant problem } & \multicolumn{3}{|c|}{ Preventing more use } \\
\hline & $\gamma_{e s}$ & No & Total & $\gamma_{e s}$ & No & Total \\
\hline Yes & 20 & 27 & 47 & 19 & 28 & 47 \\
\hline No & 27 & 121 & 148 & 20 & 128 & 148 \\
\hline Total & 47 & 148 & 195 & 39 & 156 & 195 \\
\hline
\end{tabular}

who had not $\left(\chi^{2}(1)=10.23, p=0.001, \varphi=0.23\right)$. Differences were also significant among responses of whether groping prevented more frequent use of railway $\left(\chi^{2}(1)=14.51, p<0.001, \varphi=0.27\right)$. These results indicate those who had experienced groping consider sexual harassment on trains to be more significant and that it prevented them from using the railway more often than those who had not experienced this form of harassment.

\section{Safety perceptions}

Figure 8.1 depicts participants' safety perceptions concerning their railway use during the daytime and night-time. According to the effect sizes, there was a small gender difference in the rate of participants who answered "always" to the question measuring perceptions of safety of the train during the daytime (24.1 percent in men and 14.9 percent in women, $h=0.23$ ). There were also small gender differences in the rates of participants who answered "always" and "rarely" to the question concerning the perceived safety of trains during the night-time (15.9 percent of men vs. 7.7 percent of women, $h=0.26 ; 8.2$ percent of men and 15.4 percent of women, $h=0.23$, respectively).

There were small gender differences in perceptions of safety on railway platforms during the daytime and night-time. The effect sizes of gender on the rates of answers "always" and "rarely" were 0.25 (24.1 percent of men and 14.4 percent of women) and 0.24 (5.6 percent of men and 12.3 percent of women), respectively for the question concerning the perceptions of safety on platforms during the day, and $0.4 \mathrm{l}$ for the rate of "always" responses to the question about night-time safety (10.8 percent of men and 17.4 percent of women). These results indicate women generally feel less safe than men when using railways, particularly at night.

The most frequent problem identified on the railways by nearly 30 percent to 40 percent of all respondents was drunk passengers on both the trains and the platforms. There were medium-sized differences in perceptions of problems by gender and settings (on the train, on the platform, or to/from the station) in the numbers of people who identified sexual harassment as a significant problem. The number of women who reported this issue as a problem on the train was 47 (24.1 percent), and it was over three times that of men for the same question (for women on the question about harassment on platforms, $h=0.48$ for both differences). 

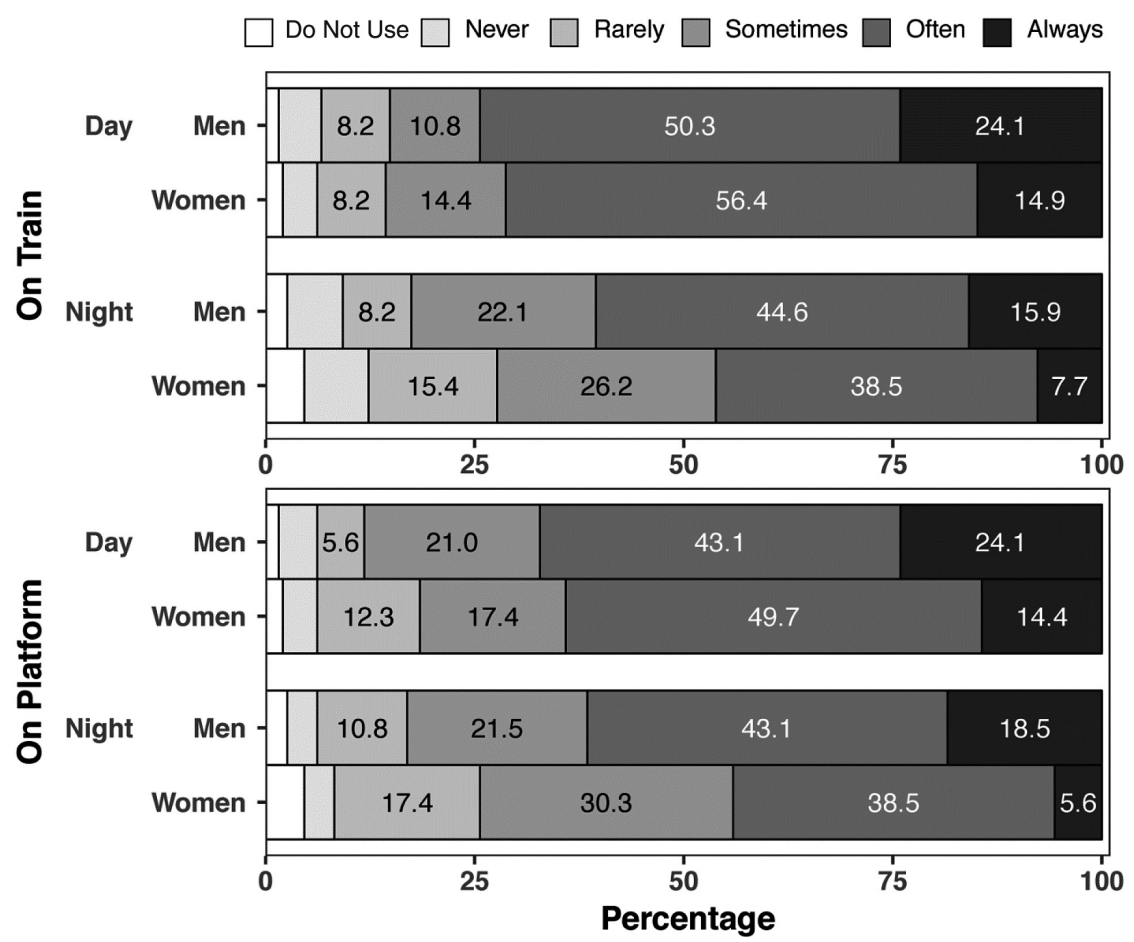

Figure 8.1 Results of participants' safety perceptions (\%) concerning their railway usage during daytime and night-time. The numbers on the low proportion groups ("never" and "do not use") are omitted.

The above-described safety conditions are confirmed by the results of the questions on factors that prevent the participants from using the railway more often (note the top four of the 16 items were the same among both men and women). The most common factor was the overcrowded service, followed by the cost, nuisance concerns, and multiple transfers, respectively. The Spearman's rank order correlation between male and female was $\rho=0.72$; thus, the overall rankings were similar for both genders. However, there was a notable difference of medium-to-large effect size in the responses concerning sexual harassment $(b=0.64)$ : the number of women who indicated this issue as a preventive factor was nearly ten times greater than that of men.

\section{Measures to improve safety}

Table 8.3 presents the number of participants who identified each of the listed measures that are expected to improve transit safety. The most effective measure was surveillance cameras in train cars or on railway platforms, as over 50 percent of the men and women believe surveillance cameras would improve the safety of 
Table 8.3 Respondents who identified measures that would make railway travel safer

\begin{tabular}{|c|c|c|c|c|c|c|c|}
\hline Measures & Total & $\%$ & Men & $\%$ & Women & $\%$ & $b$ \\
\hline $\begin{array}{l}\text { Survey cameras inside } \\
\text { train cars }\end{array}$ & 247 & 63.3 & 134 & 68.7 & 113 & 57.9 & 0.22 \\
\hline Survey cameras at platforms & 238 & 61.0 & 128 & 65.6 & 110 & 56.4 & 0.19 \\
\hline Police patrolling platforms & 194 & 49.7 & 99 & 50.8 & 95 & 48.7 & 0.04 \\
\hline $\begin{array}{l}\text { More police officers } \\
\text { patrolling train cars }\end{array}$ & 101 & 25.9 & 52 & 26.7 & 49 & 25.1 & 0.04 \\
\hline More lighting at platforms & 97 & 24.9 & 56 & 28.7 & 41 & 21.0 & 0.18 \\
\hline $\begin{array}{l}\text { Direct police line in each } \\
\text { train car }\end{array}$ & 84 & 21.5 & 34 & 17.4 & 50 & 25.6 & 0.20 \\
\hline Women-only cars & 83 & 21.3 & 16 & 8.2 & 67 & 34.4 & 0.67 \\
\hline $\begin{array}{l}\text { Direct police line at } \\
\text { platform }\end{array}$ & 72 & 18.5 & 34 & 17.4 & 38 & 19.5 & 0.05 \\
\hline $\begin{array}{l}\text { Digital timetable at } \\
\text { platforms }\end{array}$ & 41 & 10.5 & 23 & 11.8 & 18 & 9.2 & 0.08 \\
\hline
\end{tabular}

Note

$n=195$ in both men and women.

Cohen's $h$ is for the difference of the proportion between men and women.

railway travel. The Cohen's $h$ for proportions demonstrated there was a mediumto-large effect size difference between men and women concerning the effectiveness of women-only cars $(b=0.67)$, and the rate of women who claimed this measure would be effective in improving safety was higher than that of men.

The frequencies of female participants who agreed with the statement that surveillance cameras in train cars and/or women-only cars would improve the safety of railway travel were computed according to their encounters with groping on train cars. In this manner, the existence of differences in the women's perceptions of these security and safety measures were ascertained regarding their experiences of being groped on trains. Table 8.4 shows the

Table 8.4 Cross-tables between the experiences of groping and the perceptions of survey cameras and women-only cars among female participants

\begin{tabular}{|c|c|c|c|c|}
\hline \multirow[b]{2}{*}{ Measures } & \multirow[b]{2}{*}{ Groping } & \multicolumn{3}{|c|}{ Identified as effective } \\
\hline & & Yes & No & Total \\
\hline \multirow[t]{4}{*}{ Survey cameras } & Yes & 30 & 17 & 47 \\
\hline & & $63.8 \%$ & $36.2 \%$ & \\
\hline & No & 83 & 65 & 148 \\
\hline & & $56.1 \%$ & $43.9 \%$ & \\
\hline \multirow[t]{4}{*}{ Women-only cars } & Yes & 16 & 31 & 47 \\
\hline & & $34.0 \%$ & $66.0 \%$ & \\
\hline & No & 51 & 97 & 148 \\
\hline & & $34.5 \%$ & $65.5 \%$ & \\
\hline
\end{tabular}


resulting cross-tables in which the experience of being groped is mapped as the row and the perception of effectiveness is displayed as the column.

Table 8.4 indicates that previous groping victimization does not affect the perception of surveillance cameras and women-only cars. A slightly higher percentage of women who had experienced groping answered that having surveillance cameras would improve safety compared with those who had not faced this threat. However, the Pearson's chi-squared test revealed the difference was not statistically significant $\left(\chi^{2}(1)=0.59, p=0.443, \varphi=0.05\right)$.

\subsection{Discussion of the results}

In this study, we investigated transit safety among college students in TokyoKanagawa. The results demonstrated that fewer than half of women "always" or "often" felt safe for both trains and platforms during night-time, though most women reported feeling safe on trains and on platforms during the day. These results suggest that women feel much less safe during night-time.

\section{Experiences of groping}

The results concerning the experience of exposure to some form of harassment or crime demonstrated that 24.1 percent of female students had been exposed to groping while riding a train and this rate was by far the highest among crime experiences. The percentage of women who claimed they had experienced groping was lower than previously reported in other studies. For example, the Gender Equality Bureau Cabinet Office (2000) and the Tokyo Metropolitan Police Department (2018) reported that approximately 50 percent of women in their 20s claimed to have experienced groping at least once. The percentage obtained in this study was slightly less than half of those identified in these results. However, the responses in those reports represented participants' lifetime experience, whereas, in this study, the question regarded their experiences in the last three years only, which may account for these differences.

Although the victimization of groping occurred over ten times more on train cars than on the station platform or during their walk to/from the station, the perception of safety among female students did not differ much between these environments. According to the report from the Tokyo Metropolitan Police Department (2018), most arrests for nuisance crime occur during the morning and evening rush hours, and the number of arrests during the morning rush hours was larger than the arrests made during the evening rush hours. However, there was little difference in perceptions of train and station platform safety during the day versus at night, although the settings were perceived to be less safe at night than during the day.

Of note is that these results do not mean women do not view groping as a problem affecting their use of railway services. In response to the question asking about the factors that deter more frequent use of railway transport, 20 percent of women identified the fear of sexual harassment on the train among 
the primary factors. This percentage was nearly 10 times that for men. Also, it was the sixth-largest rate in female participants among the 16 listed items. Additionally, 24.1 percent of women considered sexual harassment to be a significant problem impacting railway use, which was the second most commonly identified item.

Additionally, over 90 percent of those who had been exposed to groping on a train did not report it to the officials, and over the half of those being groped reported it to no one. The main reason for not reporting was to avoid further trouble or that they were embarrassed, meaning the exposure to groping could have an impact on their safety perception on railway travel. Nonetheless, although the rates of those who took sexual harassment on trains more seriously were higher among those who had experienced groping, nearly 60 percent of those who had experienced groping did not consider groping on trains to be a significant problem that prevented them from using the railway often.

It is unclear the reason why this high rate of groping on the train had no significant effect on women's safety perception. However, a possible explanation is that there is no way of commuting other than using the railway; therefore, the impact of the experience could be underestimated as a means of reducing cognitive dissonance between the fact that groping occurs and that they use the railway almost daily. Similar patterns where victims tended to underestimate the impact of their own experience was also reported in rape victims. In Iwasaki (2000), none of the rape victims in her study reported the rape to the police and most of the victims explained the reason they did not report as "it was not that serious". As for this result, Iwasaki (2000) pointed out the possibility that the victims tried to protect themselves psychologically by underestimating its seriousness.

\section{Perceptions of women-only cars to tackle groping}

Over one-third of female students who responded to our survey claimed women-only cars would make railway travel safer. However, the prevalence of women in favor of women-only cars as safety measures was much smaller compared with that of people who considered surveillance cameras on trains and on platforms to be an effective anti-crime measure, which was 56 percent and 58 percent, respectively. Given that women-only cars have already been in operation over the past 15 years and yet surveillance cameras were considered effective by a higher proportion, it might be that womenonly cars are perceived to be less effective than claimed by railway companies and the police.

This assumption was also suggested by the study finding that encounters with groping on train cars did not increase the perception of female students that women-only cars were effective. Also, the number of women students who identified women-only cars as an effective means of improving railway travel safety was smaller even among those who had experienced groping than the number of women who found survey cameras in train cars helpful. 


\section{Seiji Shibata}

\section{Perceptions of surveillance cameras}

Most respondents of the survey considered surveillance cameras in train cars and on platforms to be effective safety and security instruments. Both men (nearly 70 percent) and women (nearly 60 percent) identified the cameras as a solution to the problem of crime committed in railway precincts. Approximately the same percentage of women $(57.1$ percent) and a lesser ratio of men (52.4 percent) responded that survey cameras should be installed on train cars to prevent or to reduce groping and violence on train cars in the survey conducted by the Statistics Bureau, Ministry of Internal Affairs and Communications (2002). The results of the present investigation suggest that over the last decade, railway passengers have gradually and increasingly accepted the institution of surveillance cameras inside train cars as viable security instruments.

Surveillance cameras, unlike women-only cars, have been proven to be effective in deterring groping. For example, it is said that the number of groping cases decreased by 60 percent when the Saikyo Line installed surveillance cameras on their train cars (Liu, 2011). In addition, four men who were suspected in 2017 of molesting a woman en masse on the Saikyo Line were identified through a surveillance camera recording and were arrested (Sankei Shimbun, 2017).

For men, the false accusation of groping has become a concern in their railway travel, and Okabe (2004) reported that approximately half of men took some measures, such as holding their strap handles with both hands, to avoid being wrongly accused of groping. These circumstances could explain the higher percentages of approval for surveillance cameras among men than women.

\section{Significant problems other than sexual harassment}

Overcrowding is another difficulty of railway travel and it is, perhaps, the most fundamental problem of the train services. It was, in fact, the factor most selected as a phenomenon that prevented both men and women from using the railway more frequently. According to a report by the Tokyo Metropolitan Police Department (2018), nearly 30 percent of groping cases occurred during the morning rush hours and another 20 percent during the evening rush hours. Hence, around half the molestation on train cars happens during the crowded morning and evening rush-hours. There is no doubt that congestion is one of the main environmental factors of groping.

\subsection{Conclusions, limitations and policy implications}

This study examined the safety of railway transport for women. To this end, it used survey data collected from 400 college students in Tokyo-Kanagawa, Japan. The survey results demonstrated that young women most commonly experience groping on train carriages. 
The outcomes of this investigation show that more than half of the respondents, both men and women, believed surveillance cameras in train cars would make their trip safer and approximately one-third of female respondents thought that women-only cars would do the same. The survey demonstrated equal to or greater surveillance-camera approval rates than those presented by the results of the 2002 survey conducted by the Statistics Bureau of the Ministry of Internal Affairs and Communications. Thus, the acceptance of surveillance cameras as an instrument of enhancing security seems to have gradually increased over the last decade. However, less than half the percentage of women reported in the survey by the Statistics Bureau of Ministry of Internal Affairs and Communications (2002) exhibited their approval in the survey for women-only cars as a safety measure. In addition, no difference was found in the approval rates offered by those who had experienced groping and those who had not. Thus, the effectiveness of this measure in improving women's safety during railway trips remains ambiguous as no clear relationship was established between the experiences and perceptions of women regarding groping and their attitudes toward womenonly cars.

This study shares several limitations with other studies of this type. First, our data do not include the actual usage of women-only cars by women; therefore, how many women regularly use women-only cars to avoid groping on the train remains unclear. Second, more often than not, there is a discrepancy between people's opinions and what actually proves to be effective. Because the data collected in our survey were limited to participants' subjective perceptions, we cannot determine the actual effectiveness of surveillance cameras and womenonly cars. Therefore, further and more systematic studies are needed to achieve a better understanding of college students' transit safety in Tokyo. Despite certain limitations in the data presented in this paper, studies in Japan on railway travel safety from perspectives other than the operational perspective have thus far been surprisingly few. It is hoped that this investigation can make a contribution to research on this topic

A policy implication on making railway travel safer could be derived from these results. Although the surveillance camera has been accepted as an effective safety and security instrument, no fundamental solution to the problem of groping can be found unless the problem of overcrowding is resolved. It is clear that overcrowding is the primary environmental factor facilitating groping, because around half the instances of such molestation are reported during the morning and evening rush-hours when overcrowding takes place.

Railway companies keep enhancing transportation capacity by increasing the number of trains or by adding cars to trains. However, the congestion during the morning and evening rush hours has not been substantially reduced. Several railway companies have recently started introducing commuter trains that have all seats reserved in the morning and evening commuting hours. This measure could be effective in solving the problem of congestion in the cars even though the issue of limited availability of stations and trains still exists for such services. Tokyo Metro, one of the major subway operators in Tokyo, started a trial 


\section{Seiji Shibata}

reward points system in April 2019. Reward points are given as incentives and may be used as electronic money by passengers who commute during off-peak hours (Tokyo Metro, 2019). It is hoped that such an attempt will lead to some reduction of congestion during peak hours (even though it may not mitigate the problem in its entirety, as long as the opening hours of schools and companies do not change) and, therefore, may also have an impact on sexual transit crime.

\section{References}

Ceccato, V. (2017). Women's transit safety: making connections and defining future directions in research and practice. Crime Prevention and Community Safety, 19, 276-287.

Ceccato, V., \& Loukaitou-Sideris, A. (2019). Transit safety among college students: an international study. Retrieved from www.kth.se/abe/om-skolan/inst/som/avdelningar/ urbana-studier/forskning/urban-community-sa/trygghet-i-kollektiv (accessed 20 February 2020).

Cohen, J. (1988). Statistical for the Behavioral Sciences. New Jersey: Lawrence Erlbaum Associates.

Doi, E. (2005). Single-sex cars on commuter trains cater to women in Japan. McClatchy DC Bureau. Retrieved from www.mcclatchydc.com/latest-news/article24447325. html (accessed 14 December 2019).

Dunckel-Graglia, A. (2013). Women-only transportation: how "pink" public transportation changes public perception of women's mobility. Journal of Public Transportation, $16,85-105$.

East Japan Marketing \& Communications, Inc. (2016). Shuto-ken rosen-gun to nobe riyōsha-sū/heikin jōsha jikan [The railway lines in the Greater Tokyo Area and its cumulative number of passengers/average travel time]. Retrieved 10 February 2019, from www.jeki.co.jp/transit/mediaguide/pdf/MD_matome4.pdf (accessed 14 December 2019).

Gekoski, A., Gray, J. M., Adler, J. R., \& Horvath, M. A. (2017). The prevalence and nature of sexual harassment and assault against women and girls on public transport: an international review. Journal of Criminological Research, Policy and Practice, 3, 3-16.

Gender Equality Bureau Cabinet Office. (2000). Danjo-kan ni okeru bōryoku ni kansuru chōsa [Survey on violence between men and women]. Retrieved 10 February 2019, from www.gender.go.jp/policy/no_violence/e-vaw/chousa/pdf/hllreport2-3.pdf (accessed 10 February 2019).

Iwasaki, N. (2000). Sexual victimization among Japanese college students: experiences in date/acquaintance rape and being "significant others" for the victims of sexual assaults. The Japanese Journal of Mental Health, 15, 52-61.

Kyodo News. (2018). JR east to install security cameras on all trains. The Japan Times. Retrieved from www.japantimes.co.jp/news/2018/04/03/national/jr-east-installsecurity-cameras-trains/ (accessed 10 February 2019).

Lee, A. (2017). Gender, everyday mobility, and mass transit in urban Asia. Mobility in History, 8(1), 85-94. Retrieved from www.berghahnjournals.com/view/journals/ mobility-in-history/8/1/mih080110.xml (accessed 10 February 2019).

Liu, J. (2011). Jōhō no shakai-chitsujo keisei kinō [Social order formation function of information]. Review of the Division of Correspondence Education, 14, 61-80.

Loukaitou-Sideris, A., \& Fink, C. (2009). Addressing women's fear of victimization in transportation settings. Urban Affairs Review, 44, 554-587. 
Madan, M., \& Nalla, M. K. (2016). Sexual harassment in public spaces: examining gender differences in perceived seriousness and victimization. International Criminal Justice Review, 26, 80-97.

National Police Agency (2015). WHITE paper on crime 2015. Retrieved 10 February 2019, from http://hakusyol.moj.go.jp/jp/62/nfm/mokuji.html (accessed 20 February 2020).

Neupane, G., \& Chesney-Lind, M. (2014). Violence against women on public transport in Nepal: sexual harassment and the spatial expression of male privilege. International Journal of Comparative and Applied Criminal Justice, 38, 23-38.

Nomura, T. (2017). On the activities of railroad police squads. IATSS Review, 41, 13-16.

Okabe, C. (2004). Study of the "carriage for women only". Kurume Shin-Ai Women's College Bulletin, 27, 57-66.

Omata, K. (2002). Long-term psychological Aftereffects of sexual victimization and influence of victim-assailant relationship upon them among Japanese female college students. Japanese Journal of Criminal Psychology, 40, 1-19.

Omata, K. (2012). The relationship of sexual victimization to risk perception of Japanese female college students. Surugadai University Studies, 44, 143-154.

Otaka, M. (2017). Survey on the incident of "Chikan" to University students. Bulletin of the Graduate School, Toyo University, 54, 65-76.

Sankei Shimbun (2017). JR Saikyō-sen de josei torikakomi shūdan-chikan utagai, 4 nin taiho [Four men arrested on JR Saikyo Line with the suspect of group groping]. The Sankei Shimbun. Retrieved from www.sankei.com/affairs/news/171127/afr1711270 020-nl.html (accessed 20 February 2020).

Statistics Bureau, Ministry of Internal Affairs and Communications (2002). Josei no shiten kara mita kōtsū-sābisu ni kansuru ankēto-chōsa [Survey on transport service from women's perspective]. Retrieved 11 February 2019, from www.mlit.go.jp/kisha/ kisha02/15/150813/150813_3.pdf (accessed 20 February 2020).

Statistics Bureau, Ministry of Internal Affairs and Communications (2010). 2010 Japan Census. Retrieved 10 February 2019, from www.stat.go.jp/data/kokusei/2010/ final/pdf/01-11_5.pdf (accessed 20 February 2020).

Suzuki, S. (2000). Jakunen-josei ni okeru chikan higai no jittai [Victimization by molesters among young females]. Research on Prevention of Crime and Delinquency, 40, 137-145.

Tokyo Metro (2019). Metopo wo katsuyō shita ofupīku purojekuto wo jisshi shimasu! [We will start an off-peak project using metopo!]. Retrieved from www.tokyometro. jp/news/images_h/metroNews20190315_27.pdf (accessed 18 December 2019).

Tokyo Metropolitan Police Department (2018). Konna jikan, basho ga nerawareru [Crime risks are high in these times and places]. Retrieved 10 February 2019, from www.keishicho.metro.tokyo.jp/kurashi/higai/koramu2/koramu8.html (accessed December 2019).

Whitzman, C. (2013). Women's safety and everyday mobility. In C. Whitzman, C. Legacy, C. Andrew, F. Klodawsky, M. Shaw, \& K. Viswanath (Eds.), Building Inclusive Cities: Women's Safety and the Right to the City (pp. 35-52). London: Routledge. 